\title{
Native-speakerism in ELT: A Survey of the Attitudes of Students and Teachers in China*
}

\author{
LIU Jun-shuan \\ Hebei University of Science \& Technology, Shijiazhuang, Hebei, China
}

\begin{abstract}
This article reports part of the findings of an investigation into the attitudes of Chinese English as a foreign language (EFL) education students and teachers toward Native-speakerism. Data were collected through two sets of questionnaires from 976 students and 146 teachers engaged in College English (CE) programs at six Chinese universities. The analysis of data reveals that the participants as an entirety: (a) endorse native speaker (NS) teachers, NS English and pronunciation; (b) anticipate the localization of teaching approaches emanating from the English speaking West; and (c) expect English textbooks multicultural in content. It was also found that teachers are more supportive of NS teachers and NS English while Inner Circle (Kachru, 1985) teaching approaches and multicultural textbooks are more popular with students. All these findings indicate the persistence of Native-speakerism in China's EFL education as well as the ideological resistance from Chinese EFL education stakeholders.
\end{abstract}

Keywords: Native-speakerism, attitude, EFL education, China, students, teachers

\section{Introduction}

Native-speakerism as a culturist ideology has long been observed predominant in global English language teaching (ELT) or teaching English to speakers of other languages (TESOL) (Holliday 2005). This is particularly true of ELT in Expanding Circle countries (Kachru, 1985), where superiority is usually granted to native speaker (NS) English, native English speaker teachers (NESTs), NS culture-embedded teaching materials and teaching methodologies that emanate from the English speaking West. This long-practiced pro-nativeness ideology is being challenged by the dynamics and fluidity of the English language in the current era of globalization as well as the concomitant critical scholarship, for example, World Englishes (WEs) (e.g., Seargeant, 2012), English as a lingua franca (ELF) (e.g., Jenkins, 2007) and English as an international language (e.g., Matsuda, 2012). Alongside this sociolinguistic reality of the English language and the academic critique are the efforts made by institutions and English language teachers "to create a nondiscriminatory professional environment for all TESOL members regardless of native language and place of birth” (Braine, 2010, p. 4).

\footnotetext{
${ }^{*}$ Note: This study adopts the terminologies, such as Inner Circle, Outer Circle, Expanding Circle, English, culture and teaching methodology, NS (native English speaker), NESTs (native English speaker teachers) or NNESTs (nonnative English speaker teachers), etc. As with many researchers (e.g., Phan, 2008; Saraceni, 2015), I am aware of the limitations of these terms. For instance, there is no unified English language and monolithic culture across Inner Circle countries, no country adopts a single teaching methodology, and not all NESTs or NNESTs are the same. In this study, these terms are adopted as conceptual tools.

LIU Jun-shuan, Dr., Department of English, School of Foreign Languages, Hebei University of Science \& Technology, Shijiazhuang, Hebei, China.
} 
Observed by the studies on the mentality of ELT stakeholders regarding the nativeness versus nonnativeness dichotomies in respect of English language teacher (e.g., Choi, 2016; Ma, 2012), the English language (e.g., Jenkins, 2007; Scales et al., 2006), cultural orientation of ELT (e.g., Chinh, 2013; Rafieyan et al., 2013) and teaching methodology (e.g., Chang, 2011; Hiep, 2007), the conventional pro-nativeness ideology still manifests a strong momentum of growth with regard to English language varieties whereas anti-Native-speakerism voices on the other three dichotomies are audible. A similar situation is also revealed in the relatively small quantity of studies that focus on the context of English as a foreign language (EFL) education in mainland China (e.g., He \& Miller, 2011; Wang, 2013; Rao, 2002), where the Native-speakerism ELT paradigm has been followed due to the historical inequitable power relations between China and the English speaking West as well as the pro-nativeness ideology in national English syllabi issued by China's Ministry of Education (MOE) (Gong \& Holliday, 2013). This complicated phenomenon represents the dynamics of discursive and ideological conflicts in most societal domains, in which the dominant discourse or ideology usually constructs mainstream social attitudes while resistance from below often transforms or reshapes the dominant discourse and socially shared beliefs in truth value or normative validity (Fairclough, 2013; van Dijk, 2008). Valuable as the findings are, most of these studies are descriptive in approach, with insufficent attention attached to the sociocultural and historical-political factors surrounding the focused ELT settings. In addition, each of the studies concentrates on one or two aspect(s) of ELT, without exploring Native-speakerism in a holistic manner by taking more dimensions of ELT into account.

In light of the discursive and ideological struggles on Native-speakerism, the theoretical and methodological limitations of existing literature as well as the current gigantic size of China's EFL education (390 million English learners, Wei \& Su, 2012), an empirical study has been conducted to investigate the attitudes of Chinese EFL education stakeholders on Native-speakerism in respect of English language teachers, English language varieties, cultural orientations of ELT and teaching methodologies. It is intended to find out whether —if so, to what extent—Native-speakerism continues to serve as the "regime of truth" (Foucault, 1984) in realm of EFL education in China. This article only reports part of the findings on the attitudes of Chinese EFL students and teachers in line with the three following questions.

1. What types of English language teachers, English language varieties, English accents, cultural content of English textbooks and teaching approaches are upheld as the ideal by Chinese EFL students and what reasons they articulate to justify their preferences?

2. What are the ideal for Chinese EFL teachers and the reasons they maintain?

3. Are there any (dis)similarities between students and teachers in attitude and in reason?

\section{Participants and Instruments}

Data were collected through two sets of questionnaires-part of the instruments adopted in this study—from 976 students and 146 teachers engaged in College English (CE) education at six Chinese universities, a two-year English program for most non-English-major undergraduate students in China. Both purposive and convenient sampling principles (Bryman, 2012, p. 202) are observed in recruiting the participants.

Suggested by Table 1, 45.59\% (445) of the 976 students are males and 54.41\% (531) are females. They come from three different disciplinary areas, including engineering (558), social science and humanities (329), and business (89). 
Table 1

Gender, Discipline Distribution of Student Participants

\begin{tabular}{lcccccccc}
\hline & \multicolumn{3}{c}{ Engineering } & \multicolumn{2}{c}{ Social science \& humanities } & Business & \multicolumn{2}{c}{ Total } \\
\cline { 2 - 9 } & \multicolumn{3}{c}{ N\% } & \multicolumn{3}{c}{ N\% } & N\% & N\% \\
\hline Male & 310 & 31.76 & 109 & 11.17 & 26 & 2.66 & 445 & 45.59 \\
Female & 248 & 25.41 & 220 & 22.54 & 63 & 6.46 & 531 & 54.41 \\
Total & 558 & 51.17 & 329 & 33.71 & 89 & 9.12 & 976 & 100 \\
\hline
\end{tabular}

Table 2 summarizes the demographic information of 146 teacher participants. 80.82\% (118) are female and 19.18\% (28) male. Four (2.74\%) hold doctoral degrees, 114 (78.08\%) master's and 28 (19.18\%) bachelor's. They also differ in professional rank, with 13 (8.90\%) being professors, 26 (17.81\%) associate professors, 76 (52.05\%) lecturers and 11 (7.53\%) teaching assistants.

Table 2

Gender, Discipline Distribution of Teacher Participants

\begin{tabular}{|c|c|c|c|c|c|c|c|c|c|c|c|c|c|c|c|}
\hline \multirow[b]{3}{*}{ Male } & \multirow{3}{*}{$\begin{array}{l}\frac{\mathrm{PhD}}{\mathrm{N} \%} \\
21.37\end{array}$} & \multirow{2}{*}{\multicolumn{2}{|c|}{$\begin{array}{l}\text { MA } \\
\text { N\% }\end{array}$}} & \multirow{2}{*}{\multicolumn{2}{|c|}{$\begin{array}{l}\mathrm{BA} \\
\mathrm{N} \% \\
\end{array}$}} & \multirow{2}{*}{\multicolumn{2}{|c|}{$\begin{array}{l}\text { Prof } \\
\mathrm{N} \% \\
\end{array}$}} & \multicolumn{2}{|c|}{ Associate Prof } & \multicolumn{2}{|c|}{ Lecturer } & \multicolumn{2}{|c|}{$\begin{array}{l}\text { Teaching } \\
\text { assistant }\end{array}$} & \multicolumn{2}{|c|}{ Total } \\
\hline & & & & & & & & & N\% & & J\% & & $\%$ & & N\% \\
\hline & & 18 & 12.33 & 8 & 5.48 & 4 & 2.74 & 6 & 4.11 & 15 & 10.27 & 3 & 2.05 & 28 & 19.18 \\
\hline Female & 21.37 & 96 & 65.75 & 20 & 13.70 & 9 & 6.16 & 20 & 13.70 & 61 & 41.78 & 8 & 5.48 & 118 & 80.82 \\
\hline Total & 42.74 & 114 & 78.08 & 28 & 19.18 & 13 & 8.90 & 26 & 17.81 & 76 & 52.05 & 11 & 7.53 & 146 & 100 \\
\hline
\end{tabular}

In the questionnaires for students and teachers, there are a pair of paralleled sections, which comprise multi-choice questions, identical in content with slight changes in wording. Different from those utilized by Timmis (2002) and $\mathrm{He}$ and Zhang (2010), the questions were extended to five items to do with learning/teaching orientations of students/teachers in scenarios where different types of teachers, English language varieties, English accents, textbooks and teaching approaches are available for choice. In addition to making choices, participants are asked to supply reasons (see the appendix). It is noted that data collected through these paralleled items are drawn upon in this article.

\section{Findings}

This section reports on the findings in line with the five sets of paralleled questions concerning the attitudes of the participants and the reasons they stated to do with different types of English language teachers, English language varieties, cultural orientations of ELT textbooks and teaching approaches. Inter-group (dis)similarities are also presented. As such, it answers the three research questions. To make reading easy, each question is described succinctly before the presentation of the results.

\section{NESTs as the owner of English and/or expert in English culture}

Question Item 1 aims to locate the attitudes of students and teachers toward four types of English language teachers different from each other in first language background. Teacher A refers to a NS from an Inner Circle country; Teacher B is a NS with a Chinese pedigree; Teacher C comes from an Outer Circle country (Kachru, 1985); Teacher $D$ is a local Chinese EFL teacher.

As shown by Table 3, most of the participants expressed strong preference for Teachers A and B. However, minor inter-group differences are also observable. Within the student group, the strongest favor was accorded to Teacher B (45.4\%), followed by Teacher A (31.1\%). By contrast, 57.5\% of the teachers selected Teacher A and 29.5\% chose Teacher B. 
Table 3

Response Frequencies for Question Item 1

\begin{tabular}{llllll}
\hline I want (my students) to attend the class of Teacher A/B/C/D. & A & B & C & D & Total \\
\hline Students & $31.1 \%$ & $45.4 \%$ & $4.1 \%$ & $19.4 \%$ & $100 \%$ \\
Teachers & $57.5 \%$ & $29.5 \%$ & $1.4 \%$ & $11.6 \%$ & $100 \%$ \\
\hline
\end{tabular}

Notes. Students $(\mathrm{N}=976)$; Teachers $(\mathrm{N}=146)$.

The dominant reasons for choosing Teacher A among the teachers and students are similar, and can be divided into three categories: (a) Teacher A has English the mother tongue; (b) Teacher A knows more about English culture; and (c) It is beneficial for students to learn English and its concomitant culture with Teacher A. Reproduced below are the typical reasons collected.

Because Teacher A comes from an English speaking country, with English as the mother tongue, he/she knows more about the culture of English speaking countries, and is familiar with the rules on how to use English. (Student No. 127)

The English language of Native English teachers is real and authentic, their pronunciation is standard, and they have profound knowledge of the English culture. They can lead students to experience real Anglo-American culture. (Teacher No. 132)

Most of the students who chose Teacher B claimed that Teacher B also speaks real, authentic English and that they feel in heart close to him/her due to the shared ethnic origin. Similar opinions are observable among teachers in favor of Teacher B. As for the inter-group difference in percentage, the crucial reason may reside in that most of the teachers would rather believe that White Anglo-Saxon Caucasians are the real owners of the English language and culture. This racist attitude is represented explicitly in their answers. For instance,

If no difference exists in teaching qualification, White Anglo-American teachers may be more acceptable to students, because the knowledge they have on English culture has been accumulated for many generations. (Teacher No. 36)

\section{NS English as Standard English (StE) and the representative of English culture}

Question Item 2 is intended to locate the attitudes of students and teachers toward three English language varieties, named as Variety A, Variety B and Variety C in line with Inner Circle English (Anglo-American English in particular), Outer Circle English varieties and China English.

Suggested by Table 4, Variety A enjoys great popularity within both participant groups. This pro-nativeness attitude is more predominant among the teachers in that $85.6 \%$ of the teachers expressed endorsement for this variety, about $19 \%$ higher than the students making the same choice (68\%).

Table 4

Response Frequencies for Question Item 2

\begin{tabular}{lllll}
\hline I want (my students) to learn Variety A/B/C. & A & B & C & Total \\
\hline Students & $68 \%$ & $18.8 \%$ & $13.2 \%$ & $100 \%$ \\
Teachers & $85.6 \%$ & $12.3 \%$ & $2.1 \%$ & $100 \%$ \\
\hline
\end{tabular}

Notes. Students $(\mathrm{N}=976)$; Teachers $(\mathrm{N}=146)$.

Major reasons supplied by the students and teachers in support of Variety A resonate with the conventional StE ideology and the anthropological episteme about the inseparability of language and culture. This is evident from the typical answers presented below. 
I think that American or British English are Standard English. Once you learn it, it will be easier for you to be understood, when you communicate with others. (Student No. 672)

The American and British English symbolize Anglo-American culture. I choose them because they are representative of that culture. (Student No. 773)

The difference in percentage between teachers (85.6\%) and students (68\%) in choosing Variety A could be ascribed to multiple factors, such as teachers' own educational experiences (We taught British or American English while at school. Teacher No. 3), the current educational regulations (We are required to teach British or American English. Teacher No. 87) and the cultural content of English textbooks (All textbooks are about British and American English, and so I teach them. Teacher No. 123). In addition, many teachers chose to teach Variety A because they expected to meet the demand of their students. As a teacher put it,

All students want to learn Standard English and its culture. Besides, most of the students who want to go abroad to pursue further study usually take UK or USA at the destination. (Teacher No. 21)

\section{NS or NS-like accent as a symbolic and practical capital}

Question Item 3 is about the attitudes of students and teachers toward different English accents. It lists three types of students for choice. Student A is almost indistinguishable from a NS in accent; Student B has a slight Chinese accent; Student C speaks English with a heavy Chinese accent, which, however, does not affect his/her communication with (non)native English speakers.

Similar to the findings of Question Items 1 and 2 that suggest a strong pro-nativeness attitude, the overwhelming endorsement is also granted to NS or the approximated NS accent (see Table 5). $44.7 \%$ and $46.2 \%$ of the students and $47.3 \%$ and $48.6 \%$ of the teachers chose Student A and B respectively. Almost no difference in percentage exists between the two groups.

Table 5

Response Frequencies for Question Item 3

\begin{tabular}{lllll}
\hline I want (my students) to be like Student A/B/C. & A & B & C & Total \\
\hline Students & $44.7 \%$ & $46.2 \%$ & $9.1 \%$ & $100 \%$ \\
Teachers & $47.3 \%$ & $48.6 \%$ & $4.1 \%$ & $100 \%$ \\
\hline
\end{tabular}

Notes. Students ( $\mathrm{N}=976)$; Teachers $(\mathrm{N}=146)$.

For the students who chose Student A, two predominant reasons were found. One comes from the belief that to acquire NS accent is a symbol of personal capability and personal achievement. For example, a student (No. 283) argued that "To be able to speak English like a native English speaker represents your learning ability and qualification." The second has to do with the assumed practical value of the NS accent. In other words, "To have the NS accent, you will find it easy to find a job in a joint venture company and then you will feel superior to others" (Student No. 781). This value is also shared by most of the teachers who selected Student A. In addition, many teachers believe that to achieve NS accent is the objective of EFL education. As one teacher (No. 106) put it, "It is the ultimate goal of English learning business to help students to acquire the NS pronunciation or the pronunciation approximate to it."

In terms of the favor for Student B, the predominant viewpoint held by the teachers is that it is almost impossible to acquire the NS pronunciation completely, though they deemed NS accent as the ideal. This is evident in the statements, such as "It is totally impractical for most adult students to get rid of the Chinese 
accent" (Teacher No. 83), but "it is a misfortune to take Student C as the model” (Teacher No. 48). Although the reason of impracticality was also held by some students, a large number of other students who chose Student B considered it a symbol of national identity to have a slight Chinese accent.

Multicultural pursuit as a political mission and/or globalization need

Question Item 4 provides three types of textbooks for choice, aimed at finding out the perceptions of students and teachers on the traditional orientation toward learning/teaching Inner Circle culture in ELT. Textbook A is based solely on Anglo-American culture; Textbook B is dominated by Anglo-American culture, but incorporates a small portion of Chinese culture. In Textbook C, the cultural content of Inner Circle countries, China and various other countries is almost equal in proportion.

Findings of this question are different from those of the three others discussed above (see Table 6). Textbook A received the least support from both students and teachers. Of all the students, $44.7 \%$ selected Textbook B and $40.1 \%$ chose Textbook C. In comparison, Textbook B and Textbook C were supported respectively by $52.1 \%$ and $28.8 \%$ of the teachers. Of the inter-group difference in preference for each textbook, the significant one lies in the choice of Textbook C.

Table 6

Response Frequencies for Question Item 4

\begin{tabular}{lllll}
\hline I want (my students) to use Textbook A/B/C. & A & B & C & Total \\
\hline Students & $15.3 \%$ & $44.7 \%$ & $40.1 \%$ & $100 \%$ \\
Teachers & $19.2 \%$ & $52.1 \%$ & $28.8 \%$ & $100 \%$ \\
\hline
\end{tabular}

Notes. Students $(\mathrm{N}=976)$; Teachers $(\mathrm{N}=146)$.

With regard to the strong preference for Textbooks B and C among the teachers, the frequently stated reason rests with their understandings of the goal of ELT in China. Most of them asserted that transmitting Chinese culture to the world should be one of the important objectives, and therefore textbooks of these two types would be beneficial in that "They can help students learn how to express Chinese culture in English" (Teacher No. 52). However, many teachers who chose Textbook B considered it more appropriate to incorporate only a small proportion of Chinese culture, claiming that "We need focus more on British or American culture, since all students are Chinese and they know Chinese culture” (Teacher No. 37).

In comparison, students held similar and even more radical stance when choosing Textbooks B and C. They asserted that one of the major objectives of ELT is to help students "not to learn about Anglo-American culture, but to use English to express learners' own cultures in cross-cultural communications” (Student No. 650). The cultural globalization in the current era serves as another reason stated for their choice. As a student stated,

On this large stage of the globalization, the contact or merge of different cultures is a symbol of our modern world. English textbooks should represent different cultures. (Student No. 429)

Localized teaching approaches as a pedagogical practicability

Question Item 5 is aimed at investigating the attitudes of teachers and students toward different English language teaching approaches. Approach A refers to original version of CLT and/or its upgraded version, the approach of Task-based Language Teaching (TBLT) practiced in Inner Circle countries; Approach B is a version of CLT/TBLT modified according to the educational culture in China; Approach $\mathrm{C}$ refers to the traditional "teacher-centered" pedagogical approach in China. 
Observed from Table 7, most of the participants expressed preference for Approach B. This is much more evident among the teachers, $87.0 \%$ of whom expected the localization of Inner Circle CLT/TBLT. By contrast, Approach A was selected by about one third of the student participants. As to Approach C, it was almost rejected by both students and teachers.

Table 7

Response Frequencies for Question Item 5

\begin{tabular}{lllll}
\hline I want (my teacher) to use teaching Approach A/B/C. & A & B & C & Total \\
\hline Students & $34.3 \%$ & $59.1 \%$ & $6.6 \%$ & $100 \%$ \\
Teachers & $9.6 \%$ & $87.0 \%$ & $3.4 \%$ & $100 \%$ \\
\hline
\end{tabular}

Notes. Students $(\mathrm{N}=976)$; Teachers $(\mathrm{N}=146)$.

For the students and teachers who chose Approach B, the most popular reason is that CLT/TBLT from the Inner Circle countries represents an advanced education philosophy, but should be modified according to the teaching and learning culture in China as well as the learning need of students and their actual English proficiency. Exemplifying reasons are presented below.

We are living in a non-English-speaking country. To use the modified TBLT approach is more beneficial for us to learn English. (Student No. 338)

The application of ELT methods in China must take the educational culture of China into consideration. The original British or American ELT pedagogical model cannot succeed in China, and is particularly inapplicable to ELT for non-English majors. (Teacher No. 89)

For the students who chose Approach A, no concrete reasons were provided except that they expected to experience the original CLT/TBLT. This may be able to explain the inter-group difference in preference for Approaches A and B.

From the findings through the five questions, it is evident that NESTs and NS English received a strong support among the students and teachers. This is aligned with pro-nativeness mentality discovered in other studies, particularly those that focus on ELT in China (e.g., Hu, 2004, 2005; Kirkpatrick \& Xu, 2002). In addition, the overwhelming favor for multicultural textbooks and the localization of CLT/TBLT corroborates the findings of Zhang and Ma (2004) and Rao (2002).

\section{Discussion}

This article reports part of the results of a study conducted to explore whether-if so, to what extent-ELT in China is still affected by Native-speakerism. In particular, it presents part of the findings of the questionnaire surveys of the attitudes held by Chinese EFL teachers and learners toward Native-speakerism to do with English language teachers, English language varieties, cultural orientations of ELT and teaching approaches. Data analysis suggests an attitudinal complex. On the one hand, predominant preference is accorded to NESTs, Inner Circle English and NS or NS-like pronunciation. Major reasons supplied by the participants are related to the StE ideology, the anthropological episteme of the inseparability between language and culture, and the symbolic value of NS English. On the other hand, dominant preference is expressed for multicultural textbooks and the localization of Inner Circle teaching approaches, CLT/TBLT in particular. Reasons stated for endorsing multicultural textbooks reside in considerations about the promotion of Chinese culture as well as the reality of cultural globalization. However, most of the participants in favor of localized CLT/ELT did not provide 
specific reasons except the concern about pedagogical suitability. Between the two participant groups, teachers are more supportive of NS language norms whereas students grant more preference for multicultural textbooks and Inner Circle CLT/TBLT. However, almost no difference has been found in regard to accent preference.

The predominant preference for NESTs, NS English and NS accent revealed in this study seems to prove the limited ideological effects of the academic and institutional endeavors of critical linguists and ELT practitioners to fight Native-speakerism. Conversely, it suggests the impact of the pro-nativeness ELT paradigm followed traditionally in China, with learners expected to achieve the NS competence (Hu \& Mckay, 2012; Wen, 2012). This pro-nativeness ideology has been (re)constructed by a series of national English syllabi issued by the Chinese MOE since the adoption of "Open Door Policy” in late 1970s (e.g., MOE, 2007, 2011). In the meantime, the pro-nativeness criterion stipulated by regulations on the employment of foreign teachers of English (e.g., SAOFEA, 2015) helps to legitimate the prestige of NESTs. Since education in China is controlled by the government, these policies and regulations are executed faithfully in ELT practices, resulting in a reified discourse or ideology that the Inner Circle English is the authentic English language and that English should best be taught by NESTs, as if all Chinese EFL learners should or have to acquire the Inner Circle English (Gong \& Holliday, 2013). Following these lines of thoughts, it can be concluded that the Native-speakerism paradigm in ELT tradition and the governmentality of EFL education in China are accountable for the widespread support of NESTs by most participants and for the frequently heard pro-nativeness voices, such as "Inner Circle English is real, authentic English".

Resistance to Native-speakerism could be seen from the positive attitudes of the students and teachers toward multicultural textbooks and their expectation for the localization of Inner Circle teaching approaches, particularly CLT/TBLT. With regard to the former, the frequently uttered voice by most of the participants is that one of the objectives of learning English is to transmit Chinese culture to the world. Although it is difficult to locate the exact source of this positioning, it may be related to the "English as threat" thesis that arose in China toward the end of the 20th century and/or to China's current economic status in the world (Pan \& Seargeant, 2012). As for the opposition to Inner Circle teaching approaches, most teachers and students simply stated that the approaches should be modified in accordance with the educational culture of China for the sake of pedagogical applicability. However, it seems that the participants may not realize that Inner Circle teaching approaches or methods are colonial constructs (e.g., Kumaravadivelu, 2016; Pennycook, 1998), invented for learners to acquire NS language and sociocultural norms by correcting their learning habits and culture of learning (Holliday, 2005). Despite this possible limitation, this voice represents the ideological changes across the ELT terrain in China.

The inter-group attitudinal differences can be interpreted in reference to the different social and educational experiences of the two groups of participants, as a person's opinion on social entities usually “depends on [his/her] early attitudes or ideologies ... as well as [his/her] personal experiences” (van Dijk, 2008, p. 15). Pre-service teacher education should be resorted to in making sense of the stronger preference of the teachers for NS teachers and NS language. In China, most of EFL teachers are English majors and graduated from normal or teacher education universities. This is also true of the teachers in this study. As a rule, EFL programs for English major students in China require students to attain NS or NS-like competence in English. Such pre-service education experience might have nurtured among the teachers a pro-nativeness "habitus" (Bourdieu, 1984). The traditional Confucianism on the authoritative identity of teachers in China and other Eastern Asian countries may account for the expectation among the teachers for localizing Inner Circle 
teaching approaches, which seems to reduce the authority of teachers as the owner of knowledge due to its proposed “student-centered” and “autonomous learning” pedagogy (Hiep, 2007; Phan, 2008). In the same vein, the stronger preference for multicultural textbooks and Inner Circle CLT/TBLT among the student group can be ascribed to their social and educational experiences. In this study, most of the students were born in late 1990s. Since then, China has been experiencing globalization and promoting CLT/TBLT on a large scale in EFL education. These experiences may account for those students' stronger awareness of cultural globalization as well as their inclination to accept Inner Circle teaching methodology.

\section{Conclusion}

What is reported in this article suggests an attitudinal complex among Chinese EFL teachers and students and by extension the current ideological effects of Native-speakerism on EFL education in China. It is evident Native-speakerism still finds its firm foothold in China's ELT but encounters resistance in others. Albeit these valuable findings, there is one weak point in this article, i.e., treating each participant group as a homogeneous entity, without taking intra-group variables into consideration. This weakness is expected to be patched up in future studies.

\section{References}

Bourdieu, P. (1984). Distinction: A social critique of the judgement of taste. London: Routledge.

Braine, G. (2010). Non-native-speaker English teachers. Wiley Online Library.

Bryman, A. (2012). Social research methods (4th ed.). Oxford: Oxford University Press.

Chang, M. (2011). EFL teachers' attitudes toward communicative language teaching in Taiwanese college. Asian EFL Journal, 53(1), 17-34.

Chinh, N. D. (2013). Cultural diversity in English language teaching: Learners' voices. English Language Teaching, 6(4), 1-7.

Choi, L. J. (2016). Revisiting the issue of native speakerism: “I don’t want to speak like a native speaker of English”. Language and Education, 30(1), 72-85.

Fairclough, N. (2013). Critical discourse analysis: The critical study of language. London: Routledge.

Foucault, M. (1984). The Foucault reader. New York: Pantheon.

Gong, Y., \& Holliday, A. (2013). Cultures of change: Appropriate cultural content in Chinese school textbooks. In K. Hyland and L. L. C. Wong (Eds.), Innovation and change in English language education (pp. 44-57). New York: Routledge.

He, D., \& Miller, L. (2011). English teacher preference: The case of China's non-English-major students. World Englishes, 30(3), 428-443.

He, D., \& Zhang, Q. (2010). Native speaker norms and China English: From the perspective of learners and teachers in China. TESOL Quarterly, 44(4), 769-789.

Hiep, P. H. (2007). Communicative language teaching: Unity within diversity. ELT Journal, 61(3), 193-201.

Holliday, A. (2005). The struggle to teach English as an international language. Cambridge: Cambridge University Press.

Hu, G., \& McKay, S. L. (2012). English language education in East Asia: Some recent developments. Journal of Multilingual and Multicultural Development, 33(4), 345-362.

$\mathrm{Hu}$, X. (2004). Why China English should stand alongside British, American, and the other "world Englishes”. English Today, 20(2), 26-33.

Hu, X. (2005). China English, at home and in the world. English Today, 21(3), 27-38.

Jenkins, J. (2007). English as a Lingua Franca: Attitude and identity. Oxford: Oxford University Press.

Jenkins, J. (2012). English as a Lingua Franca from the classroom to the classroom. ELT Journal, 66(4), 486-494.

Kachru, B. B. (1985). Standards, codification and sociolinguistic realism: The English language in the outer circle. In R. Quirk and H. G. Widdowson (Eds.), English in the world: Teaching and learning the language and literature (pp. 10-30). Cambridge: Cambridge University Press.

Kirkpatrick, A., \& Xu, Z. (2002). Chinese pragmatic norms and “China English”. World Englishes, 21(2), 269-279.

Kumaravadivelu, B. (2016). The decolonial option in English teaching: Can the subaltern act? TESOL Quarterly, 50(1), 66-85. 
Liu, Y., Zhang, J. L., \& May, S. (2015). Research on textbook culture based on the corpus of national planned College English textbooks. Foreign Language World [Yai Yu Jie], (6), 85-93.

Ma, L. P. F. (2012). Advantages and disadvantages of native- and nonnative-English-speaking teachers: Student perceptions in Hong Kong. TESOL Quarterly, 46(2), 280-305.

Matsuda, A. (2006). Negotiating ELT assumptions in EIL classrooms. In J. Edge (Ed.), (Re-)locating TESOL in an Age of Empire (pp. 158-170). Basingstoke: Palgrave Macmillan.

Matsuda, A. (2012). Principles and practices of teaching English as an international language. New perspectives on language and education. Bristol: Multilingual Matters.

MOE. (2007). Daxue yingyu kecheng jiaoxue yaoqiu [English curriculum requirements for institutions of higher learning]. Beijing: Ministry of Education.

MOE. (2011). Yingyu kecheng biaozhun [English curriculum standard]. Beijing: Ministry of Education.

Pan, L., \& Seargeant, P. (2012). Is English a threat to Chinese language and culture? English Today, 28(03), 60-66.

Pennycook, A. (1998). English and the discourses of colonialism. London: Routledge.

Phan, L. H. (2008). Teaching English as an international language: Identity, resistance and negotiation. Clevedon: Multilingual Matters.

Rafieyan, V., Eng, L. S., \& Mohamed, A. R. (2013). Language learners' attitudes towards the incorporation of target language culture into foreign language instructions. International Journal of Linguistics, 5(4), 169-177.

Rao, Z. (2002). Chinese students' perceptions of communicative and non-communicative activities in EFL classroom. System, 30(1), 85-105.

SAOFEA. (2015). Waiguo zhuanjia laihua gongzuo xuke fuwu zhinan [Work permit service guidance for foreign experts to work in China]. Beijing: Chinese National Foreign Expert Bureau.

Saraceni, M. (2015). World Englishes: A critical analysis. London: Bloomsbury Academic.

Scales, J., Wennerstrom, A., Richard, D., \& Wu, S. H. (2006). Language learners' perceptions of accent. TESOL Quarterly, 40(4), 715-738.

Seargeant, P. (2012). Exploring world Englishes: Language in a global context. London: Routledge.

Timmis, I. (2002). Native-speaker norms and international English: A classroom view. ELT Journal, 56(3), 240-249.

van Dijk, T. A. (2008). Discourse and power. New York: Palgrave Macmillan.

Wang, Y. (2013). Non-conformity to ENL norms: a perspective from Chinese English users. Journal of English as a Lingua Franca, 2(2), 255-282.

Wei, R., \& Su, J. (2012). The statistics of English in China. English Today, 28(03), 10-14.

Wen, Q. (2012). Teaching English as an international language in mainland China. In A. Kirkpatrick and R. Sussex (Eds.), English as an international language in Asia: Implications for language education (pp. 79-93). New York: Springer.

Zhang, B., \& Ma, L. (2004). An investigation of the cultural content of college-English course books foreign language world. [Wai Yu Jie], 105(4), 60-66. 


\section{Appendix: Paralleled section of the questionnaires for teachers and students}

There are three to four descriptions under each question item. Please make your favorite choice and provide the reasons.

1. Of the following four English language teachers with almost the same teaching qualifications, whose class do you want (your students) to attend most?

Teacher A: a native English speaker from an Inner Circle country

Teacher B: a native English speaker from an Inner Circle country, but with a Chinese pedigree

Teacher C: a person from an Outer Circle country, with English as his/her first language

Teacher D: a local Chinese English teacher, with English as a foreign language

Your choice:

Reasons:

2. Of the following three English varieties, which one do you want to teach (learn) most?

Variety A: Inner Circle English, British or American English in particular

Variety B: Outer Circle English, such as Indian English, Singaporean English, etc.

Variety C: China English (an English variety representing the typical features of Chinese culture)

Your choice:

Reasons:

3. Which of the following student do you prefer (your students) to be?

Student A: His/her pronunciation is indistinguishable from that of a native English speaker.

Student B: He/she has a slight Chinese accent.

Student C: He/she speaks English fluently with a heavy Chinese accent, but it does not affect his/her communication with (non)native English speakers.

Your choice:

Reasons:

4. Of the following three sets of English as a foreign language (EFL) textbooks with different cultural content, which one is your favorite in teaching (learning) English?

Textbook A: focusing merely on Inner Circle culture, particularly British and/or American culture

Textbook B: incorporating not merely Inner Circle culture, particularly Anglo-American culture, but also a small portion of Chinese culture

Textbook C: cultures of Inner Circle countries, China and other countries equally distributed

Your choice:

Reasons:

5. Of the following three teaching approaches, which one do you prefer most?

Approach A: the communicative language teaching (CLT) approach or its upgraded version, task-based Language Teaching (TBLT) approach from Inner Circle countries

Approach B: a version of CLT/TBLT modified according to the educational culture in China

Approach C: the conventional "teacher-centered” teaching approach in China

Your choice:

Reasons: 